\title{
Revoluções Tecnológicas e Transformações Subjetivas
}

\author{
Ana Maria Nicolaci-da-Costa ${ }^{1}$ \\ Pontifícia Universidade Católica do Rio de Janeiro
}

\begin{abstract}
RESUMO: Muitos psicólogos acham difícil acreditar que as tecnologias digitais, e principalmente a Internet, possam gerar mudanças na organização subjetiva de homens e mulheres contemporâneos. Paradoxalmente, estes psicólogos reconhecem que a organização subjetiva característica dos séculos XIX e XX - a do indivíduo - emergiu como resultado das mudanças desencadeadas pela Revolução Industrial. Por isso mesmo, este trabalho examina os aspectos que a Revolução das Tecnologias da Informação e a Revolução Industrial têm em comum. Explora, principalmente, as conseqüências humanas de ambas procurando tornar claro que algumas tecnologias podem gerar profundas transformações subjetivas, cuja compreensão é fundamental para a psicologia.
\end{abstract}

Palavras-chave: transformações subjetivas; tecnologia; Internet; Revolução Industrial; Revolução das Tecnologias da Informação.

\section{Technological Revolutions and Subjective Transformations}

\begin{abstract}
Many psychologists find it hard to believe that the new digital technologies, and mainly the Internet, may be transforming the subjective organization of contemporary men and women. Ironically, these psychologists admit that the subjective organization characteristic of the $19^{\text {th }}$ and $20^{\text {th }}$ centuries - that of the individual - emerged as a result of similar changes introduced by the Industrial Revolution. For this reason, the present paper analyzes the aspects that the Information Technology Revolution and the Industrial Revolution have in common. It focuses on the human consequences of both in order to show that some technologies can cause deep subjective transformations, whose understanding is fundamental to psychology.
\end{abstract}

Keywords: subjective transformations; technology; Internet; Industrial Revolution; Information Technology Revolution.

Todos reconhecemos que inovações tecnológicas dos mais variados tipos introduzem transformações em nossas vidas. Além das transformações que presenciamos em primeira mão, somos capazes de ter acesso a inúmeras outras quando estabelecemos contato, por meio de relatos dos mais velhos, livros, filmes, viagens, etc., com os modos de vida de épocas e lugares em que uma ou outra tecnologia ainda era desconhecida. Esse tipo de contato com o antes de determinada tecnologia, torna fácil perceber as transformações por ela geradas no depois.

Quem não sabe que, antes da energia elétrica, a família se reunia ao redor do piano? Quem desconhece que, depois da energia elétrica, o piano foi substituído pelo rádio e, ainda mais recentemente, pela televisão? Alguém que tenha uma geladeira que já parou de funcionar pode desconhecer as transformações que este eletro-doméstico gerou na nossa relação com o mercado de suprimentos? Quantos de nós, acostumados que estamos às calculadoras de bolso, ainda sabemos fazer contas de cabeça ou na ponta do lápis?

Não parece haver dúvidas de que nossos comportamentos e hábitos podem sofrer alterações em função do desenvolvimento de novas tecnologias. $\mathrm{O}$ difícil é perceber que algumas tecnologias têm impactos bem mais profundos sobre os seres humanos que a ela são expostos, chegando mesmo, embora em raros casos, a gerar transformações internas

1 Endereço: Departamento de Psicologia - Rua Marquês de São Vicente, 225 - Gávea - 22543-900 Rio de Janeiro - RJ - E-mail: anicol@psi.pucrio.br radicais. Em outras palavras, embora seja fácil detectar que novas tecnologias têm o poder de alterar nossos hábitos e nossas formas de agir, é bem mais difícil registrar que algumas tecnologias também podem alterar radicalmente nossos modos de ser (como pensamos, como percebemos e organizamos o mundo externo e interno, como nos relacionamos com os outros e com nós mesmos, como sentimos, etc.).

Do ponto de vista da psicologia, essa dificuldade tornase particularmente preocupante em um momento ímpar, como o que estamos vivendo neste início do século XXI, em que as novas Tecnologias da Informação ${ }^{2}$ se expandem, penetram todo o tecido social e transformam o planeta na Aldeia Global preconizada por Marshall McLuhan (ver McLuhan e Powers, 1986). Preocupante porque, embora seja visível para praticamente todos que tudo está mudando muito, e numa velocidade assustadora, não parece ser tão visível, para muitos profissionais que se dedicam a diversos tipos de atendimento psicológico, que nós - os homens e mulheres desta virada de século e de milênio - também estamos passando por transformações internas radicais em função de nossa exposição a essas novas tecnologias.

2 Está sendo adotada a seguinte definição de Tecnologias da Informação, proposta por Castells (2000): o conjunto convergente de tecnologias em microeletrônica, computação (software e hardware), telecomunicações/radiodifusão, e optoeletrônica. Castells também inclui, nos domínios da tecnologia da informação, a engenharia genética e seu crescente conjunto de desenvolvimentos e aplicações. Esta inclusão foge, no entanto, aos objetivos deste artigo. 
No que se segue, tento tornar claro que é exatamente isso que está acontecendo. Para tanto, revisito os cenários que reconhecidamente levaram à emergência da organização psicológica - a do indivíduo - vista como característica do século XX (ao menos no Ocidente). Com a ajuda de autores clássicos e contemporâneos, exploro o período de grandes transformações sociais e subjetivas que se seguiu às descobertas de diferentes fontes de energia inanimada nos séculos XVIII e XIX. Procuro identificar semelhanças e diferenças nos processos de mudança externa e interna, desencadeados então, e naqueles que estamos vivendo neste início de século. A partir dessa análise, argumento que, tal como aconteceu naquela época, a organização psicológica contemporânea está sendo profundamente transformada por desenvolvimentos tecnológicos e que a psicologia não pode ficar alheia a isso.

\section{Revisitando a Revolução Industrial a Partir da Ótica das Transformações no Sistema Produtivo}

O sociólogo Manuel Castells é, talvez, um dos principais autores contemporâneos que se dedicam a buscar semelhanças e diferenças entre o que está acontecendo nos dias de hoje em decorrência da difusão das Tecnologias da Informação e o que aconteceu nos séculos XVIII e XIX em função da descoberta de fontes de energia inanimada.

No primeiro volume de sua trilogia A Era da Informação: Economia, Sociedade e Cultura (2000), antes de dar início à sua extensa análise dos efeitos da Revolução das Tecnologias da Informação, Castells procura identificar os fatores que transformam o desenvolvimento de uma nova tecnologia em uma revolução tecnológica. Restringindo o escopo de sua análise aos últimos 250 anos, ${ }^{3}$ julga ser importante fazer um levantamento dos aspectos invariantes daquelas que vê como as duas Revoluções Industriais: a desencadeada no final do século XVIII pela descoberta da energia a vapor e aquela gerada, na segunda metade do século XIX, pela invenção da energia elétrica. ${ }^{4}$ Segundo ele, entre as duas há muitas diferenças que, pelo próprio fato de serem cruciais, ressaltam os aspectos que ambas têm em comum. E são exatamente as características partilhadas por diferentes revoluções geradas por diferentes desenvolvimentos tecnológicos que, a seu ver, oferecem subsídios preciosos para uma compreensão da lógica das revoluções tecnológicas. Entre essas, destacam-se as seguintes:

3 Interessantes análises de outras revoluções tecnológicas, e de suas conseqüências subjetivas, podem ser encontradas em Teixeira (1971) e Zaremba (2001). Já históricos abrangentes da evolução das tecnologias podem ser consultados em Basalla (1988) e McClellan III e Dorn (1999).

4 Como veremos adiante, vários autores encaram a invenção da energia elétrica apenas como um estágio posterior do processo revolucionário iniciado com a descoberta da energia a vapor. Tal divergência, porém, apenas tangencia a presente discussão. Portanto, para facilitar a exposição, a divisão feita por Manuel Castells será mantida ao longo deste texto. (a) uma transformação tecnológica em aceleração e sem precedentes em comparação com os padrões históricos,

(b) a difusão das novas tecnologias por todo o sistema econômico,

(c) a penetração dessas mesmas tecnologias em todo o tecido social.

Quanto às diferenças, talvez por conta de seu grande interesse na geração de novas tecnologias e nos impactos destas sobre os modos de produção, Castells aponta explicitamente apenas uma: a de que somente a invenção da energia elétrica se baseou em conhecimentos científicos.

Em outro ponto, no entanto, ao comparar as conseqüências do surgimento das tecnologias da informação e da invenção da energia inanimada, Castells introduz uma outra importante diferença entre a primeira e a segunda Revoluções Industriais. Escrevendo sobre a Revolução das Tecnologias da Informação, diz: "Este é ..., no mínimo, um evento histórico da mesma importância da Revolução Industrial do século XVIII, introduzindo um padrão de descontinuidade nas bases materiais da economia, sociedade e cultura." (p. 50, meus itálicos)

Em outras palavras, Castells afirma que a introdução de um padrão abrangente de descontinuidade radical com a ordem precedente foi uma característica da primeira mas não da segunda Revolução Industrial. Essa diferença é reforçada mais adiante quando, citando o historiador de tecnologia $\mathrm{R}$. J. Forbes (p. 56), enfatiza que a invenção da máquina a vapor foi o fator central na revolução industrial.

A descontinuidade radical com a ordem das coisas precedente, que é extremamente importante para a avaliação de impactos psicológicos como veremos abaixo, soma-se, portanto, às características mencionadas anteriormente na montagem de um quadro inicial dos aspectos que a primeira e a segunda Revoluções Industriais e a Revolução das Tecnologias da Informação têm ou deixam de ter em comum, segundo Castells.

Todas têm em comum a aceleração sem antecedentes históricos, o fato de atuar no processo central de todos os processos (a energia, no caso das Revoluções Industriais, e a informação, no caso da Revolução das Tecnologias da Informação), a difusão por todo o sistema econômico e a penetração em todo o tecido social. Somente a segunda Revolução Industrial e a Revolução das Tecnologias da Informação, no entanto, têm em comum o fato de se basear em conhecimentos científicos (a esse respeito, ver também Sevcenko, 2001). E somente a primeira Revolução Industrial e a Revolução das Tecnologias da Informação têm em comum o fato de gerar descontinuidades profundas nos mais variados setores da vida em sociedade.

\section{Revisitando a Revolução Industrial a Partir da Ótica de suas Conseqüências Humanas}

As análises de Castells são provocativas e instigantes. Apresentam, porém, uma séria limitação quando vistas da ótica deste artigo. Dado que a atenção de Castells está principalmente voltada para o impacto das novas tecnologias no 
sistema produtivo e na economia, suas análises podem servir somente como ponto de partida para a compreensão do que acontece com os seres humanos durante cujo tempo de vida ocorre um processo de transformação social radical. Por conta de seus macro objetivos, os insights psicológicos de Castells não são de grande monta. Há, portanto, que complementar suas análises com as de outros autores, tanto clássicos quanto contemporâneos. Isso será feito a seguir.

Em um primeiro momento, será discutida e aprofundada a questão da descontinuidade. Isso porque, a julgar pelo que dizem vários analistas (principalmente aqueles interessados nos impactos humanos da nova sociedade industrial), a ruptura radical com a ordem precedente é o grande diferencial entre a primeira e a segunda Revoluções Industriais. É também o que aproxima a primeira Revolução Industrial da Revolução das Tecnologias da Informação, pelo menos no que diz respeito àquela de suas vertentes que maior impacto teve nas últimas décadas - a da conexão dos computadores em rede - que chamaremos de Revolução da Internet. ${ }^{5}$ Uma vez estabelecido o papel central dessa ruptura, a presente discussão concentrar-se-á na primeira Revolução Industrial e na Revolução da Internet.

Tendo em vista que uma descontinuidade radical e abrangente com a ordem anterior é forçosamente multifacetada, serão apresentadas algumas das facetas que as rupturas introduzidas por esses dois processos revolucionários têm em comum. Estas não foram estudadas por Castells. São elas: a geração de novos espaços de vida, as alterações de amplo alcance nos estilos de agir, de viver e de ser dos homens e mulheres que lhes foram contemporâneos e a proliferação de vocábulos que expressam novos interesses, novas necessidades, novas formas de vida, novos relacionamentos, novos conflitos, etc. Antes disso cabe, como anunciado, retomar e aprofundar a discussão da descontinuidade.

\section{Retomando a questão da descontinuidade}

A descontinuidade instaurada pela primeira Revolução Industrial foi radical, acelerada e desorientadora. É isso o que dizem vários de seus analistas.

Paul Kennedy (1993), por exemplo, ressalta a sua radicalidade. Dá exemplos dramáticos do aumento de produtividade que se seguiu aos momentos iniciais da substituição do trabalho humano pelas ferramentas mecânicas e da força animal pela energia inanimada. Um desses exemplos diz respeito ao setor de tecelagem. Kennedy relata que os primeiros teares movidos a vapor já podiam produzir 20 vezes mais do que um trabalhador manual e que as primeiras máquinas para fiar movidas à energia já tinham 200 vezes a capacida-

5 As Tecnologias da Informação estão por trás de vários desenvolvimentos tecnológicos recentes: computadores, telefonia digital fixa, telefonia celular, etc. Seu maior impacto foi, no entanto, gerado pela conexão de computadores em rede. A Revolução das Tecnologias da Informação é também conhecida por outros nomes como, por exemplo, Revolução Digital, Revolução da Microeletrônica, e Revolução Informacional. de da roca. A partir desses e de outros dados, afirma que nenhuma descoberta tecnológica anterior havia produzido alguma coisa semelhante ao enorme salto à frente na produtividade gerado pela Revolução Industrial desde os seus primeiros momentos. ${ }^{6}$

Já a rapidez da transformação, além da radicalidade, é registrada, entre muitos outros, pelo sociólogo Robert Nisbet (1966) no que diz respeito às reações dos intelectuais da época. Tudo aconteceu tão rápida e abruptamente que, dependendo da relação que mantinham com a antiga ordem e com as forças nela operantes, muitos desses intelectuais se sentiram ou aterrorizados e nostálgicos ou intoxicados e excessivamente otimistas frente às transformações que presenciavam. Em sua abrangente análise das principais obras da sociologia clássica, Nisbet torna evidentes as influências que tais sentimentos nelas exerceram.

É, no entanto, o historiador Eric Hobsbawn (1969) quem melhor descreve a desorientação que se seguiu às devastadoras alterações sociais geradas pelos novos modos de produção. Segundo ele, a Revolução Industrial:

... transformou a vida dos homens além do que se podia perceber. Ou, sendo ainda mais preciso, em seus estágios iniciais, destruiu o antigo modo de vida, deixando-os livres para descobrirem ou fazerem, para eles próprios, outros caminhos, se pudessem e soubessem como. (p. 80, meus itálicos)

Em Hobsbawn, portanto, novamente encontramos a observação de que cabe aos primeiros estágios do processo de descobertas sucessivas, que caracterizou a Revolução Industrial como um todo, a responsabilidade pela introdução de mudanças radicais na vida de seus contemporâneos.

\section{Outras características que a primeira Revolução Industrial e a Revolução da Internet têm em comum}

A descontinuidade parece ser a grande responsável tanto pela transformação do modo de vida feudal, dominante no século XVIII, no modo de vida capitalista, que passou a vigorar no século XIX, quanto pelas profundas transformações sociais recentemente introduzidas pela nova ordem digital.

E, como já foi dito, pelo próprio fato de terem sido radicais e abrangentes, essas rupturas foram multifacetadas. Muitas dessas facetas - e seus indicadores visíveis - são comuns a essas duas revoluções mas foram inexploradas por Castells. Passemos à sua discussão.

\section{As novas formas de organização social geraram a emergência de novos espaços de vida.}

Retornemos mais uma vez aos acontecimentos dos dias que se seguiram à invenção da primeira fonte de energia inanimada.

6 Esses primeiros momentos são eloqüentemente descritos pela romancista inglesa Charlotte Brontë em Shirley, originalmente publicado em 1849 (Brontë, 1849/1983). 
As recém-implantadas formas de produção industrial rapidamente geraram novas formas de organização social que se desenrolavam em um novo espaço: o dos grandes centros urbano-industriais. Essa foi uma mudança visível e impactante. Por isso mesmo, segundo Nisbet (1966), o urbanismo rapidamente se tornou um dos principais temas do pensamento social do século XIX. As paixões ideológicas por ele despertadas são prova da importância que assumiu. ${ }^{7}$ Seguem-se alguns exemplos de diferentes posições dignas de nota.

De acordo com Nisbet, enquanto Marx via o surgimento do urbanismo como um dos aspectos positivos do capitalismo, Engels expressava angústia em relação à sua difusão. Este dizia:

Sabemos muito bem que o isolamento do individuo ... é, em todos os lugares, o princípio fundamental da sociedade moderna. Mas em nenhum lugar esse egotismo é tão ruidosamente evidente quanto no alvoroço frenético da grande cidade. (Engels, citado em Nisbet, 1966, p. 29, minha tradução)

Já Tocqueville tinha uma visão mais equilibrada. Escrevia, após uma visita à cidade de Manchester, no berço da Revolução Industrial:

Deste fétido escoadouro flui a maior corrente da indústria humana para fertilizar o mundo inteiro. Deste imundo esgoto flui ouro puro. Aqui a humanidade alcança o seu mais completo e o seu mais selvagem desenvolvimento, aqui a civilização realiza seus milagres e o homem civilizado é transformado em um selvagem. (Tocqueville, citado em Nisbet, 1966, p. 29, minha tradução)

Vários outros grandes pensadores do século XIX e início do XX também dedicaram atenção ao fenômeno urbano.

Sem adotar uma visão pessimista ou otimista da cidade, Simmel (ver Wolff, 1964) investigou em detalhes diversos tipos de agrupamentos urbanos, estudou questões relativas a diferentes tipos de relacionamento interpessoal, ao segredo e à privacidade e identificou novas formas de ser características do urbanita. Já para Weber (1922/1978), a cidade se constituiu em uma via de acesso para o estudo da origem e do desenvolvimento do capitalismo. Freud não escreveu explicitamente sobre a cidade, mas fica claro, em vários pontos de sua obra (ver, principalmente, 1930/1980), que o que entendia por civilização estava intimamente associado à vida urbana.

É, no entanto, Wirth quem melhor descreve a importância do novo espaço urbano nas modernas sociedades capitalistas. Em um artigo intitulado "O urbanismo como modo de vida", cuja primeira publicação data de 1938, Wirth diz:

7 A importância atribuída ao urbanismo fez surgir uma nova área dentro da sociologia: a da sociologia urbana. A esse respeito, ver Velho (1987). O filme Metropolis, dirigido por Fritz Lang na década de 1920, também é um bom indicador do grande interesse despertado, no início do século XX, pelos novos espaços urbano-industriais.
A característica marcante do modo de vida do homem na idade moderna é a sua concentração em agregados gigantescos. (...) As influências que as cidades exercem sobre a vida social do homem são maiores do que poderia indicar a proporção da população urbana, pois a cidade não somente é, em graus sempre crescentes, a moradia e o local de trabalho do homem moderno, como é o centro iniciador e controlador da vida econômica, politica e cultural que atraiu as localidades mais remotas do mundo para dentro de sua órbita... (Wirth, 1938/ 1987, p. 90)

Um resultado análogo ao do surgimento dos grandes espaços urbano-industriais vem sendo gerado pelo desenvolvimento da Internet. Esta, segundo seus vários analistas, também gerou um novo espaço. A esse respeito não há discordâncias. As divergências ocorrem somente por conta das definições dadas a esse novo espaço e das propriedades a ele atribuídas por diferentes autores.

Em linha com seus interesses macro sociológicos, Castells (2000), por exemplo, define o novo espaço como um espaço de fluxos, ou seja, como a organização material das práticas sociais de tempo compartilhado que funcionam por meio de fluxos. Os suportes materiais desse espaço de fluxos são, segundo ele, constituídos por circuitos de impulsos eletrônicos, por seus nós e centros de comunicação. Em outras palavras e de modo mais simples, o espaço de fluxos é gerado por redes de computadores. Esse mesmo espaço recebe, no entanto, outros nomes e descrições.

Um de seus principais analistas, Pierre Lévy (1996, 1999), adota o nome que lhe foi dado pelo romancista norte-americano William Gibson: ciberespaço. Define-o como a corporificação do caos, a essência da cibercultura. Diz:

O ciberespaço está organizado com um sistema de sistemas mas, mesmo assim, é também um sistema do caos. Corporificação máxima da transparência técnica, (...) ele desenha e redesenha a aparência de um labirinto móvel (...) Essa universalidade destituida de significado central, esse sistema da desordem, essa transparência labiríntica, que eu chamo de 'Universal sem totalidade', constitui a essência paradoxal da cibercultura. (1999, p. 192, minha tradução)

Já, Christian Crumlish, autor do Dicionário da Internet (1997), o define como o espaço no qual é compartilhada a realidade imaginária criada pelas redes de computadores.

É justamente essa característica de ser um lugar imaginário, no qual é compartilhada uma realidade também imaginária, que atrai a atenção daqueles que estão interessados em entender as conseqüências humanas da Revolução da Internet. Isso porque é surpreendente o poder que esse novo espaço e essa nova realidade têm de cativar e prender seus freqüentadores.

Turkle (1995) mostra como é possível viver nesse espaço e nessa realidade. Nicolaci-da-Costa (1998), Romão-Dias (2001) e Costa (2001) também deixam claro que o ciberespaço é o lugar (embora desprovido de materialidade física) no qual se experimentam novas formas de vida a partir das telas dos computadores que lhes servem de plataforma e via de acesso. Enquanto isso, Young (1998) alega que as experi- 
ências nele vividas são tão atraentes e tão reais e intensas que podem levar ao vício.

Resumindo, o ciberespaço é para a Revolução da Internet aquilo que a metrópole foi para a Revolução Industrial.

\section{As novas formas de organização social e os novos espaços de vida geraram profundas alterações nos estilos de agir e de ser de seus contemporâneos.}

Alheio às paixões ideológicas que o urbanismo despertava em seus contemporâneos, o sociólogo alemão Georg Simmel voltou sua atenção para vários aspectos do cotidiano nos grandes centros urbano-industriais. Em "A metrópole e a vida mental", publicado pela primeira vez em 1902 (Simmel, 1902/1987, ver também Wolff, 1964), já chamava a atenção para o papel modernizador que as metrópoles tinham sobre os comportamentos e os modos de ser de seus habitantes.

Segundo ele, o cotidiano nesses novos espaços introduzia vários novos elementos na vida do urbanita: o excesso de estímulos, a divisão entre locais de trabalho e de moradia, a separação entre os domínios do público e do privado, os diferentes círculos de conhecimento, a racionalidade, a frieza, o anonimato, a reserva, o isolamento, o cálculo, a mobilidade, a pontualidade, etc. A essas novidades, correspondiam novos comportamentos e novos traços psíquicos.

Ao fazer uma comparação da vida numa metrópole com a vida na antiga ordem feudal, Simmel lançava as bases para a compreensão do que é hoje conhecido como a construção social da subjetividade. Dizia em um artigo que se tornou um clássico:

... de cada ponto da superficie da experiência (...) pode-se deixar cair um fio de prumo para o interior da profundeza do psiquismo, de tal modo que todas as exterioridades mais banais da vida estão, em última análise, ligadas às decisões concernentes ao significado e estilo de vida. (Simmel, 1902-3, em Velho, 1987, p. 15)

O que Simmel queria dizer é que novos espaços colocam em operação novas necessidades, novas demandas, novas regras de produção, sociabilidade, sobrevivência, etc. Como resultado de tudo isso, emergem novas formas de agir e de viver que dão visibilidade aos processos de transformação das formas de ser.

Não foi ele, todavia, o único a assinalar o poder que o cotidiano nos grandes centros urbano-industriais tinha de gerar transformações internas de cunho individual.

O sociólogo francês Emile Durkheim (1897/1982), contemporâneo de Simmel, também apontava as conseqüências psicológicas da nova ordem social. A sociedade industrial era bem mais plural, mais permissiva e menos coesa do que a comunidade feudal. Por isso mesmo, o novo todo social, se comparado ao que o havia antecedido, perdera seu poder de coerção e de contenção do desejo individual. A liberdade individual resultante podia parecer inebriante, mas freqüentemente tinha conseqüências bastante negativas. A principal delas era a perda de referenciais - a anomia - que podia levar as pessoas ao suicídio. Este é um dos fatores aos quais Durkheim atribui as altas taxas de suicídio das grandes cidades de sua época.

As conseqüências negativas da liberdade individual resultante da vida nas modernas sociedades industriais figuravam também entre os vários fatores que levaram um outro grande pensador do século XIX, Sigmund Freud, à análise de uma nova organização subjetiva: a do indivíduo. Seguese uma ilustração que tem diretamente a ver com a questão da contenção do desejo individual que acaba de ser discutida. De forma simplificada, segundo Freud, na ausência de uma instância externa de controle do desejo individual (instância essa que fora destruída quando do esfacelamento dos laços de coesão da comunidade feudal), o homem moderno havia sido levado a erigir uma instância de controle interna, o superego. Isso, por sua vez, havia alterado profundamente sua estrutura psíquica bem como a dinâmica de funcionamento desta. O ódio e a frustração, por exemplo, antes canalizados para agentes externos que proibiam a satisfação de um desejo, passaram a ser dirigidos para uma instância de controle interna ao próprio sujeito e deram origem a comportamentos neuróticos. A partir desse e de muitos outros insights, Freud mostrou que a vida predominantemente urbana do homem moderno havia introduzido importantes alterações em seus comportamentos e em sua própria organização psicológica.

Estas e muitas outras mudanças nos modos de agir, de viver e de ser dos homens e mulheres do século XIX e início do século XX foram registradas por vários outros autores (ver, por exemplo, Ariès ,1962, Habermas ,1978, Perrot, 1992 e Shorter, 1977). Não me deterei nelas, no entanto. Cabe mudar de revolução e de século para dar continuidade à presente exposição.

A primeira constatação a que se chega quando se examina o que já foi produzido sobre a Revolução da Internet é a de que a história se repete. Tal como aconteceu antes, as novas formas de organização social (virtual e em rede) e o novo espaço (imaginário porém vivido como concreto) geraram (e ainda vêm gerando) alterações não somente nos comportamentos, mas também na constituição psíquica dos homens, mulheres e crianças dos nossos dias.

Testemunhos disso podem ser encontrados na farta literatura sobre os efeitos do uso da Internet produzida a partir de sua difusão em meados da década de 1990 (tempo recorde pelos padrões tradicionais). Seguem-se alguns exemplos, que podem ser classificados em três grandes categorias: (a) registros de alterações superficiais de comportamento (as mais fáceis de serem detectadas); (b) relatos de comportamentos vistos como problemáticos, bem como de conflitos internos gerados pelo uso da Internet; e (c) registros, descrições e análises das transformações que estão ocorrendo na própria organização subjetiva de homens e mulheres de nossos dias. (Uma revisão mais minuciosa dessa literatura pode ser encontrada em Leitão e Nicolaci-da-Costa, 2000.)

Novos comportamentos são relatados por todos aqueles que se dedicaram a estudar os impactos da Internet, em maior ou menor grau de profundidade. Ainda em 1995, Negroponte 
já falava a respeito de vários deles no livro Being Digital. Em 1997, Tapscott divulgava os resultados de seu extenso trabalho sobre o uso da Internet por crianças e adolescentes em Growing up digital: the rise of the Net generation. Em 1998, Young publicava Caught in the Net, livro no qual anunciava ao mundo a emergência de um novo comportamento patológico: o uso intensivo da Internet, que ela acredita ter as características de um "vício". ${ }^{8}$ Também em 1998, Nicolacida-Costa analisava as novas formas de pensar, de escrever, de aprender, de contrair e manter relacionamentos de todos os tipos, de amar, de adquirir conhecimento sobre si mesmos, etc. dos usuários da rede internacional de computadores em Na malha da Rede: os impactos intimos da Internet. Em 2000, Zaremba, Abreu e Nicolaci-da-Costa mostravam que as crianças haviam adquirido o gosto pela escrita online em "Escrita digital: a nova pedra no sapato da escola" e, em 2001, Zaremba revelava que isso também havia acontecido com adultos em Escrevendo (ou seria 'teclando'?!) o homem do século XXI. Enquanto isso, Costa (2001) trazia a público como são intensos os relacionamentos vividos no ciberespaço em IRC: uma nova alternativa para as relações entre as pessoas.

Além de novos comportamentos, os analistas da nova ordem digital abordam, também, novos problemas e conflitos psicológicos. O vício na Internet é, como vimos acima, estudado por Young. O estresse tecnológico é o tema do livro TechnoStress, de Weil e Rosen (1997). O excesso de informação é examinado por Schenk em Data smog: surviving the information glut (1997). O sexo virtual é apontado por Virilio (1999) como uma conseqüência do atual desregramento social. $\mathrm{O}$ isolamento e a depressão são objetos de investigação de uma pesquisa de Kraut e colaboradores (2001). Os conflitos entre o prazer gerado pela vida online e a produtividade que dela se espera, bem como a emergência de novas formas de defesa da intimidade, são analisados por Nicolaci-da-Costa (2002a e 2000)

Por último, novas organizações subjetivas podem ser identificadas a partir dos resultados de investigações empíricas com usuários da Internet, realizadas por alguns pesquisadores. Em Life on the screen: identity in the age of the Internet (1995), a psicanalista norte-americana Sherry Turkle argumenta que está emergindo um novo modelo de organização psíquica em decorrência do uso da Rede. Esse modelo é o dos "múltiplos eus" (multiple selves), ou seja de sujeitos que, a exemplo do que acontece nos computadores, vivem como se fora em várias "janelas" abertas simultaneamente. No artigo "Caught in a world wide web: The Internet and the new man", Nicolaci-da-Costa (1999), tendo por base uma ampla pesquisa realizada com usuários brasileiros da Internet, primeiramente divulgada em 1998, identifica as principais características do que vê como o homem do século XXI. Um homem que, segundo ela, "pensa, age, sente, faz uso da linguagem, se relaciona consigo próprio e com os

8 Uma crítica à precipitação deste diagnóstico é feita por Nicolaci-daCosta (2002b). outros, percebe o mundo, etc. de forma diferente da de seus predecessores (incluindo ele próprio antes de a transformação acontecer)" (p. 173). Em 2001, em Nossa plural realidade: um estudo sobre a subjetividade na era da Internet, Romão-Dias revela, também a partir de dados brasileiros, um modelo subjetivo, semelhante ao dos sujeitos multiplicados de Turkle, que rompe com aquele que vigorou ao longo do século XX.

Essa ruptura é ainda analisada, muitas vezes de forma bastante cáustica e não necessariamente tendo por base pesquisas empíricas, no trabalho dos vários autores que acompanham os novos desenvolvimentos com horror. Estes registram a emergência de um modelo subjetivo diferente daquele que predominou no ocidente ao longo do século XX, o de uma subjetividade fragmentada, esquizofrênica e superficial (ver, entre outros, Jameson, 1997, Harvey, 1989 e Sennett, 1999) e de uma "identidade de palimpsesto" (Bauman,1998), sem necessariamente explorá-las em profundidade. Os mais radicais chegam a falar sobre a "morte do sujeito", ou seja, sobre o fim da mônada, do ego ou do indivíduo autônomo burguês (ver Jameson, 1997).

De qualquer modo, esses e outros estudos da subjetividade contemporânea apontam numa mesma direção: tal como a primeira Revolução Industrial deu origem a um longo processo de mudanças que resultou na emergência do homem do século XX, a Revolução da Internet desencadeou um processo de transformações, ainda em curso, que está gerando o homem do século XXI.

\section{As alterações nas formas de conceber o mundo, desencadeadas pela primeira Revolução Industrial e pela Revolução da Internet, tornaram necessária a criação de um novo vocabulário para dar conta de uma nova realidade.}

Nisbet (1966) relata uma interessante observação do historiador Eric Hobsbawn. Este afirmava que palavras falam mais alto do que documentos. Com isso, queria dizer que mudanças radicais ganham concretude nas palavras que são cunhadas para descrever uma nova realidade ou são modificadas com a mesma finalidade.

Partindo da observação de Hobsbawn, Nisbet assinala que o período compreendido entre o final do século XVIII e a primeira metade do século XIX foi, do ponto de vista do pensamento social, um dos mais ricos em formação de palavras. Desde os seus primeiros momentos, a Revolução Industrial presenciou a criação de novas palavras para fazer referência a tudo de novo que estava sendo introduzido no cotidiano da época: conceitos, preocupações, valores, modos de produção, posição social, conflitos, etc.

É de Nisbet a seguinte citação:

Considere os seguintes termos, que foram inventados durante este periodo ou - o que dá no mesmo - tiveram seus significados atualizados: indústria, industrial, democracia, classe, classe média, ideologia, intelectual, racionalismo, humanitarismo, atomístico, massas, comercialismo, proletariado, coletivismo, 
igualitário, liberal, conservador, cientista, utilitário, burocracia, capitalismo, crise. (Nisbet, 1966, p. 23)

Não há dúvidas de que, nessas palavras, podemos reconhecer temas caros ao pensamento moderno que eram desconhecidos (ou eram irrelevantes) na antiga ordem.

Essa proliferação de neologismos não ficou, no entanto, restrita à esfera do pensamento social. Ela ocorreu também em outras esferas, inclusive na do pensamento psicológico. Foram inúmeros os novos vocábulos introduzidos nas línguas vernáculas européias para descrever novos comportamentos, novas formas de ser, novos conflitos internos, novas formas de relacionamento, novos sentimentos, etc. gerados pelos novos modos de produção industrial e pela vida urbana. Anomia, inconsciente, mecanismos de defesa, ego, superego, neurose, psicose, borderline, público, privado são apenas alguns poucos exemplos escolhidos aleatoriamente. Os vários dicionários de psicologia e psicanálise dão seu testemunho dessa verdadeira torrente de novos vocábulos que descrevem uma vida interna até então inédita.

A atenção requerida por essa nova vida interna, no entanto, pode ser ainda melhor apreendida a partir de vocábulos cuja importância suplanta a de quaisquer outros: aqueles que nomeiam áreas de estudos independentes e novas como as ciências humanas e a própria psicologia (a respeito da emergência das ciências humanas e da psicologia bem como do apogeu do individualismo, ver, entre outros, Foucault, 1966 e Figueiredo, 1992). Ao longo do século XIX, as mudanças foram tantas e tão profundas que demandaram o surgimento de especialistas em questões humanas.

Voltando, agora, ao final do século XX, é fácil constatarmos que um processo análogo ocorreu quando do surgimento das tecnologias da informação. O advento dos computadores pessoais e, principalmente, da Internet fez com que novos significados fossem atribuídos a antigos vocábulos e enxurradas de novos termos e expressões - como, por exemplo, $w w w$, rede, ciberespaço, realidade virtual, tempo real, e-mail, listas de discussão, navegadores, mecanismos de busca, chats, spam, windows, menus, deletar, formatar, configurar e uma infinidade de outros - invadissem o linguajar contemporâneo em ritmo extremamente acelerado (para uma discussão mais pormenorizada dos termos e expressões que penetraram a versão brasileira da língua portuguesa, ver Nicolaci-da-Costa, 1998). ${ }^{9}$ Seguem-se alguns indicadores dessa invasão.

Em 1991, antes do boom da Internet, era publicado o Microsoft Press Computer Dictionary. Segundo a introdução à sua versão brasileira, publicada em 1992 pela Editora Campus, este havia sido criado com a finalidade de se cons-

9 A entrada de novos vocábulos nas línguas contemporâneas é visível demais para que possa ser ignorada. O mesmo não acontece no que diz respeito à alteração dos significados de vocábulos antigos. Michel Serres (ver 1991, entre outros), por exemplo, acredita que nada mudou no significado de uma palavra que tem posição central na nova realidade instaurada pela Rede mundial de computadores: a palavra virtual. Ao alegar que o virtual sempre existiu, deixa de registrar que, após a Internet, ele ganhou uma característica até então desconhecida, a interatividade em tempo real. tituir em uma fonte de definições completa e precisa para a terminologia relacionada com o uso de computadores.

É claro que essa previsão de estabilidade não se materializou. A terminologia relacionada ao uso de computadores aumentou exponencialmente com o boom da Internet, que ocorreu em meados da década de 1990. Assim é que, em 1997, a mesma editora brasileira publicava o Dicionário da Internet, cujo original inglês de autoria de Christian Crumlish data de 1995. Dele constam 2400 verbetes.

Mesmo a publicação desses e de outros dicionários não foi, no entanto, suficiente. Com a chegada da Internet ao Brasil, vários jornais e revistas passaram a publicar miniglossários semanais ou mensais, com listas de palavras e expressões representativas da nova realidade. Um pouco mais tarde, os dicionários online, bem mais fáceis de serem atualizados vieram suprir as constantes necessidades dos muitos milhões de usuários de computadores e da Internet frente a uma realidade que não parava de mudar. Tornou-se também comum encontrar, em apêndices de livros sobre a Internet, pequenos glossários dos neologismos empregados em seu texto (ver, por exemplo, Nicolaci-da-Costa, 1998).

Novamente temos a sensação de que a história se repete. E não é para menos. A primeira Revolução Industrial e a Revolução da Internet certamente têm em comum o fato de terem dado origem a uma rara proliferação de novas palavras e expressões. Palavras e expressões certamente necessárias para registrar e dar alguma concretude às mudanças desencadeadas por esses dois momentos revolucionários.

\section{Conclusão: A Produção de Conhecimento em Psicologia Frente ao Constante Desenvolvimento de Novas Tecnologias}

Sabemos que a psicologia (tal como as outras ciências humanas) surgiu no século XIX. Sabemos também que isso aconteceu em função da necessidade de compreender uma nova organização subjetiva - a do indivíduo - que havia emergido em decorrência dos novos espaços, modos de produção e estilos de vida instaurados pela Revolução Industrial. Com o passar do tempo e com a relativa estabilidade alcançada ao longo do século XX, parece, no entanto, que muitos se esqueceram disso e passaram a acreditar que a estrutura e o funcionamento psíquicos do ser humano são imutáveis.

Como venho argumentando (ver Nicolaci-da-Costa, 2002a e 2002b), esse esquecimento pode ter sérias conseqüências. Se, enquanto profissionais de psicologia, acreditarmos que o ser humano não está sendo tocado pelas transformações radicais que o mundo vem sofrendo, corremos o risco de perder nossa capacidade de estudá-lo, descrevê-lo, interpretá-lo, compreendê-lo e, conseqüentemente, ajudá-lo.

Não parece ser difícil admitir que as comunidades do século XVIII deram lugar às modernas sociedades industriais e que os membros daquelas sofreram transformações que deram origem ao indivíduo dos séculos XIX e XX. Por que, então, parece ser tão difícil reconhecer que esse mesmo indivíduo pode estar tendo sua organização subjetiva modifi- 
cada a ponto de se tornar algo diferente e ainda sem nome de batismo? Se isso aconteceu antes, por que tanta relutância em admitir que possa estar acontecendo agora?

Várias são as razões que podem estar contribuindo para gerar tal relutância. Em primeiro lugar, para todos nós, leigos e profissionais, a distância no tempo atua como um neutralizador dos sentimentos gerados pela perda de algo antes considerado duradouro ou, até mesmo, eterno (no caso, a nossa própria forma de ser e estar no mundo). A mesma distância tem um outro efeito importante: permite uma visão de conjunto que torna as mudanças mais visíveis.

Já enquanto o processo está sendo vivido, como está acontecendo agora, o velho e o novo convivem lado a lado e tornam tudo muito confuso. Nesse caso, qualquer tipo de distância só pode ser alcançado artificialmente, geralmente por pesquisadores e intelectuais treinados para observar e "estranhar" o cotidiano (ver Velho, 1981). No mais das vezes, além da confusão, o turbilhão da mudança gera intensas reações nostálgicas e muito medo do desconhecido. Isso não é tudo, no entanto.

Boa parte da dificuldade em admitir a mudança radical pela qual passa a subjetividade contemporânea certamente é gerada por fatores diretamente ligados à produção de conhecimento na área da psicologia. Seguem-se alguns.

(a) Mudanças internas vão ocorrendo aos poucos. Por isso, em um primeiro momento, quando detectadas sob a forma de novos comportamentos e/ou novos conflitos, como os discutidos acima, essas mudanças parecem ser localizadas. Nesse primeiro momento, tem-se a impressão de que apenas um ou outro aspecto da organização subjetiva característica do individualismo está sofrendo alguma transformação. (As mudanças sofridas na noção de privacidade, tão discutidas nestes dias em que encontramos câmeras - de segurança ou não - em elevadores, bancos, lojas, etc., são um bom exemplo disso.)

(b) Essas mesmas mudanças são freqüentemente analisadas a partir da ótica das tradicionais teorias do indivíduo (com as quais infelizmente muitos pensam que a psicologia tem uma vinculação indissolúvel). Isso faz com que muitas vezes sejam interpretadas como patologias ou desvios ou, ainda, como uma forma de esvaziamento de algo que deveria estar lá. (Retomando o exemplo da privacidade, por conta de uma maior exposição da intimidade, feita voluntariamente nos canais de batepapo digitais, passa-se facilmente a falar de ingenuidade ou de exibicionismo. Deixa-se de levar em consideração que essa maior exposição é realizada interativamente e sob a proteção do anonimato. Por isso mesmo, torna-se impossível perceber que esse tipo de auto-exposição pode ser uma importante fonte de auto-conhecimento. $)^{10}$

(c) A produção de conhecimento sobre o novo estado de coisas, como não poderia deixar de ser, é feita pouco a

10 A exposição interativa da intimidade como uma forma de auto-conhecimento é descrita em Nicolaci-da-Costa (1998). pouco. Assim sendo, nos primeiros estágios de mudança, falta a visão de conjunto necessária para se avaliar a abrangência e a radicalidade da transformação. (Como vimos anteriormente, no entanto, já é possível vislumbrar o conjunto de transformações geradas pela Revolução da Internet.)

(d) Faltam novas leituras da subjetividade que identifiquem o novo, e não somente a morte do velho, de modo a possibilitar a construção de novas teorias que interpretem a nova realidade e a nova organização subjetiva por ela gerada. (Como também venho insistindo - ver Nicolaci-da-Costa, 1998, 1999, 2002a, 2002b - essas novas leituras da subjetividade devem ser feitas a partir de novos referenciais e não daqueles que, sendo tradicionais, podem já ter perdido seu poder explicativo. $)^{11}$

Para completar, há ainda um certo ceticismo em relação ao potencial transformador das novas tecnologias digitais e, principalmente, da Internet. Muitos vêem os novos desenvolvimentos tecnológicos como semelhantes a tantos outros que presenciamos ao longo do século XX. Não crêem, portanto, que as novas tecnologias venham a ter conseqüências mais radicais do que aquelas que já fazem parte do nosso dia-a-dia.

Creio haver argumentado exaustivamente que eles estão enganados. Necessitam de alguma distância que lhes forneça uma visão de conjunto para poder perceber que, diferentemente do que aconteceu com a Internet, mesmo as tecnologias de maior penetração no século XX (como o automóvel, o rádio, a televisão, os aviões, o cinema) não tiveram o poder de criar um espaço de vida no qual se desenrolam as mais variadas interações e dramas humanos. É exatamente essa distância (construída a partir de comparações com outras tecnologias e épocas) que se pretendeu oferecer neste artigo.

Por todos esses motivos e na medida em que, a exemplo da telefonia celular e da clonagem, novas e impactantes tecnologias não param de surgir, creio ser útil tentarmos aprender com o passado remoto e o recente para que possamos estar melhor equipados para lidar com as conseqüências psicológicas das novas tecnologias, presentes e futuras, tanto pessoal quanto profissionalmente.

11 Aqui cabem duas observações. A primeira diz respeito ao fato de que mesmo posturas vistas como inovadoras - como aquelas que têm como objetivo fazer atendimento online - muitas vezes nada inovam no que tange ao reconhecimento das mudanças subjetivas geradas pela própria tecnologia da qual se propõem a lançar mão (ao que tudo indica, continuam pressupondo a organização subjetiva tradicional, ou seja, a do indivíduo). Já a segunda observação tem a ver com o medo, que muitos parecem ter, de que a psicologia possa vir a desaparecer caso esse mesmo indivíduo deixe de existir. Em ambos os casos, está ausente o registro de que uma das principais funções da psicologia é a de descrever, interpretar e compreender as organizações subjetivas que são geradas em diferentes contextos sociais (já conhecidos ou completamente novos), nos quais as tecnologias sempre desempenharam um importante papel. 


\section{Referências}

Ariès, P. (1962). Centuries of childhood. New York: Vintage Books.

Basalla, G. (1988). The evolution of technology. Cambridge: Cambridge

University Press.

Bauman, Z. (1998). Globalização: as conseqüências humanas. Rio de Janeiro: Jorge Zahar Editor.

Brontë, C. (1849/1983). Shirley. Harmondsworth: Penguin.

Castells, M. (2000). A sociedade em Rede. São Paulo: Editora Paz e Terra.

Costa, A.C.A. (2001). IRC: uma nova alternativa para as relações entre as pessoas. Dissertação de Mestrado não-publicada, Curso de Pós-Graduação em Psicologia Clínica, Pontifícia Universidade Católica do Rio de Janeiro. Rio de Janeiro, RJ.

Crumlish, C. (1997). Dicionário da Internet. Rio de Janeiro: Editora Campus.

Durkheim, E. (1982). O suicídio: um estudo sociológico. Rio de Janeiro: Zahar Editores. (Original publicado em 1897.)

Figueiredo, L.C. (1992). A invenção do psicológico: quatro séculos de subjetivação (1500-1900). São Paulo: Escuta.

Foucault, M. (1966). Les mots et les choses. Paris: Gallimard.

Freud, S. (1980). O mal-estar na civilização. Edição Standard das Obras Psicológicas Completas de Sigmund Freud, volume xxi. Rio de Janeiro: Imago. (Original publicado em 1930).

Habermas, J. (1978). L'espace public. Archéologie de la publicité comme dimension constitutive de la société bourgeoise. Paris: Payot.

Harvey, D. (1989). Condição pós-moderna. São Paulo: Edições Loyola.

Hobsbawn, E. (1969). Industry and Empire: The Pelican economic history of Britain, volume 3, From 1750 to the present day. Harmondsworth: Pelican.

Jameson, F. (1991). Pós-modernismo: a lógica cultural do capitalismo tardio. São Paulo: Editora Ática.

Kennedy, P. (1993). Preparando para o século XXI. Rio de Janeiro: Editora Campus.

Kraut, R., Lundmark, V., Patterson, M., Kiesler, S., Mukopadhyay, T. \& Scherlis, W. (2001). Internet paradox. A social technology that reduces social involvement and psychological wellbeing? American Psychologist, janeiro de 2001. Disponível em: http://www.apa.org/journals/amp/amp5391017.html].

Leitão, C. \& Nicolaci-da-Costa, A. M. (2000). Psicologia clínica e informática: por que essa inusitada aproximação? Psicologia Clínica, 12/2, pp. 189-205.

Lévy, P. (1996). O que é o Virtual?. São Paulo: Editora 34.

Lévy, P. (1999). The universal without totality: the essence of cyberculture. Em E.R. Larreta (Org.), Media and Social Perception (pp. 191-208). Rio de Janeiro: UNESCO, ISSC, EDUCAM.

McClellan III, J. \& Dorn, H. (1999). Science and technology in world history. Baltimore: The John Hopkins University Press.

McLuhan, M. \& Powers, B. (1986). The Global Village. Transformations in world life and media in the 21st century. New York: Oxford University Press.

Microsoft Press (1992). Dicionário de Informática. Rio de Janeiro: Editora Campus.

Negroponte, N. (1995). A vida digital. São Paulo: Companhia das Letras.

Nicolaci-da-Costa, A.M. (1998). Na malha da Rede: Os impactos intimos da Internet. Rio de Janeiro: Editora Campus.

Nicolaci-da-Costa, A.M. (1999). Caught in a World Wide Web: the Internet and the New Man. Em E.R. Larreta (Org.), Media and
Social Perception (pp. 155-177). Rio de Janeiro: UNESCO, ISSC, EDUCAM.

Nicolaci-da-Costa, A.M. (2000). A tecnologia da Intimidade. Em Sociedade Brasileira de Computação (Org.), Anais do III Workshop sobre Fatores Humanos em Sistemas de Computação (pp. 155-177). Porto Alegre, RS: SBC.

Nicolaci-da-Costa, A.M. (2002a). Quem disse que é proibido ter prazer online. Identificando o positivo no quadro de mudanças atual. Psicologia: Ciência e Profissão, 22 (2), pp. 12-21..

Nicolaci-da-Costa, A.M. (2002b). Internet: a negatividade do discurso da mídia versus a positividade da experiência pessoal. À qual dar crédito? Estudos de Psicologia (Natal) , 7 (1), pp. $25-$ 36.

Nisbet, R.A. (1966). The sociological tradition. New York: Basic Books.

Perrot, M. (Org.) (1992). História da vida privada, vol. 4. Säo Paulo: Cia. das Letras.

Romão-Dias, D. (2001). Nossa plural realidade: um estudo sobre a subjetividade na era da Internet. Dissertação de Mestrado não-publicada, Curso de Pós-Graduação em Psicologia Clínica, Pontifícia Universidade Católica do Rio de Janeiro. Rio de Janeiro, RJ.

Schement, J.R. e Curtis, T. (1997). Tendencies and tensions of the Information Age. New Brunswick: Transaction Publishers.

Schenk, D. (1997). Data smog: surviving the information glut. San Francisco: Harper San Francisco.

Sennett, R. (1998). A corrosão do caráter: conseqüências pessoais do trabalho no novo capitalismo. Rio de Janeiro: Record.

Serres, M. (2001). Le virtuel est la chair même de l'homme. Le Monde, 18 de junho.

Sevcenko, N. (2001). Virando séculos. A corrida para o século $X X I$. São Paulo: Companhia das Letras

Shorter, E. (1977). Naissance de la famille moderne. Paris: Seuil.

Simmel, G. (1902/1987). A metrópole e a vida mental. Em O. G. Velho (Org.), O fenômeno urbano (pp. 11-25). Rio de Janeiro: Editora Guanabara, 1987.

Tapscott, D. (1997). Growing up digital: the rise of the Net generation. New York: McGraw-Hill.

Teixeira, A. (1971). Cultura e Tecnologia. Rio de Janeiro: Fundação Getúlio Vargas.

Turkle, S. (1995). Life on Screen: identity in the age of the Internet. New York: Touchstone Edition.

Velho, G. (1981). Individualismo e cultura. Rio de Janeiro, Zahar Editores.

Velho, O.G. (Org.) (1987). O fenômeno urbano. Rio de Janeiro: Editora Guanabara.

Virilio, P. (1999), The game of love and chance. Grand Street, 52. Disponível em: http://www.grandstreet.com/gs/gs52/virilio. html.

Weber, M. (1978). Economy and society. Editado por G. Roth e Claus Wittich. Berkeley: University of California Press. (Original publicado em 1922.)

Weil, M. e Rosen, L. (1997). TechnoStress: coping with technology@work,@home,@play. New York: John Wiley \& Sons.

Wirth, L. (1987). O urbanismo como modo de vida. Em O.G. Velho (Org.), O fenômeno urbano (pp. 90-113). Rio de Janeiro: Editora Guanabara. (Original publicado em 1938.)

Wolff, K.H. (Org.) (1964). The sociology of Georg Simmel. New York: The Free Press.

Young, K. (1998). Caught in the Net: how to recognize the signs of the Internet Addiction and winning strategy for recovery. New York: John Wiley \& Sons. 
Zaremba, R. (2001). Escrevendo (ou seria 'teclando'?!) o homem do século XXI. Dissertação de Mestrado não-publicada, Curso de Pós-Graduação em Psicologia Clínica, Pontifícia Universidade Católica do Rio de Janeiro, Rio de Janeiro, RJ.
Zaremba, R., Abreu, R.S. \& Nicolaci-da-Costa, A.M. (2000). A escrita digital: uma pedra no sapato da escola. Em Sociedade Brasileira de Computação (Org.), Anais do III Workshop sobre Fatores Humanos em Sistemas de Computação (pp. 196-202). Porto Alegre, RS: SBC.

\section{INTERESSADO EM AGILIZAR A PUBLICAÇÃO DE SEU ARTIGO?}

\section{Informações e dicas para os autores sobre aspectos operacionais}

\section{O manuscrito é reencaminhado pelo autor em versão reformulada}

A produção gráfica do trabalho é executada através de editoração eletrônica, daí a exigência do exemplar em disquete, além de três exemplares em papel da versão reformulada. Quando a versão reformulada é aceita e são poucos os reparos, as correções necessárias são feitas na secretaria da revista. Com o disquete disponível o processamento pode ser imediatamente iniciado. Na falta de disquete não é possível o processamento de correções nem a preparação do manuscrito para editoração. Em suma, atraso para entrar no prelo.

\section{Informações e dicas para os autores com artigos no prelo}

\section{O manuscrito é encaminhado para editoração}

No caso de o manuscrito ser aceito para publicação, é esperada a participação do autor no processo de preparação do artigo na fase de editoração. A primeira prova do artigo, editada a partir da versão em disquete, é enviada para exame ao(s) autor(es). O prazo para devolução é de 48 horas. A obediência ao prazo permite a manutenção da composição prevista para o volume/número da revista. $\mathrm{O}$ atraso no envio da prova examinada pode implicar em mudanças na composição de um número no prelo. E pode resultar em atraso na edição final. 